Corrigendum

\title{
Corrigendum to "The Studies of Chlorogenic Acid Antitumor Mechanism by Gene Chip Detection: The Immune Pathway Gene Expression"
}

\author{
Tian Yi Kang, ${ }^{1}$ Hua Rong Yang, ${ }^{2}$ Jie Zhang, ${ }^{2}$ Dan Li, ${ }^{1}$ Jie Lin, ${ }^{1}$ Li Wang, ${ }^{1}$ and XiaoPing Xu ${ }^{1}$ \\ ${ }^{1}$ West China School of Pharmacy, Sichuan University, Chengdu, Sichuan 610041, China \\ ${ }^{2}$ Jiuzhang Biochemical Engineering Science and Technology Development Co., Ltd., Chengdu, Sichuan 610041, China \\ Correspondence should be addressed to XiaoPing Xu; jerryxu106@163.com
}

Received 2 December 2014; Accepted 10 February 2015

Copyright (c) 2015 Tian Yi Kang et al. This is an open access article distributed under the Creative Commons Attribution License, which permits unrestricted use, distribution, and reproduction in any medium, provided the original work is properly cited.

In the paper titled "The Studies of Chlorogenic Acid Antitumor Mechanism by Gene Chip Detection: The Immune Pathway Gene Expression," Journal of Analytical Methods in Chemistry Volume 2013 (2013), Article ID 617243, 7 pages, doi: $10.1155 / 2013 / 617243$, some errors occurred in the "Disclosure" and "Acknowledgments" sections and they should be corrected as follows.

\section{Disclosure}

Jiuzhang Biochemical Engineering Science and Technology Development Co., Ltd., provided the project and fund directly. The intellectual property of the project in the paper belonged to the company. Both Chairman Jie Zhang and Dr. Hua Rong Yang were the main people responsible for the project. Authors are Researchers of Sichuan University and have no conflict of interests.

\section{Acknowledgments}

Sichuan Jiuzhang Biological Science and Technological Co., Ltd., financially supported this work. The Sichuan Province Science and Technology Support Project Fund (2011SZ0131) supported this work. The authors would like to show great thanks to Hongwei Liu for his great help. 

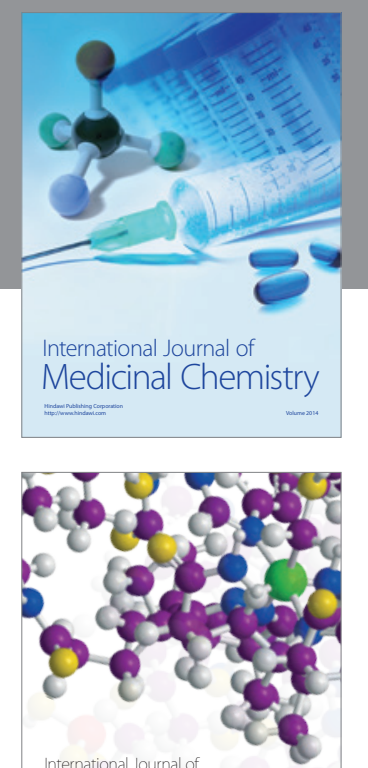

\section{Carbohydrate} Chemistry

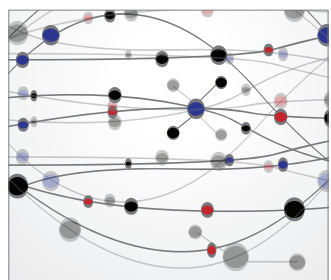

The Scientific World Journal
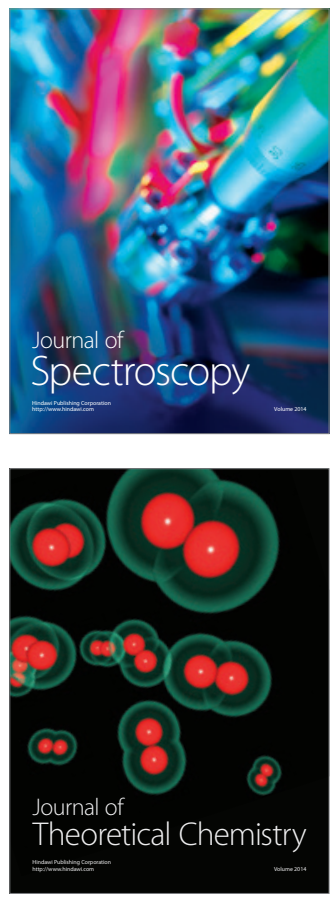
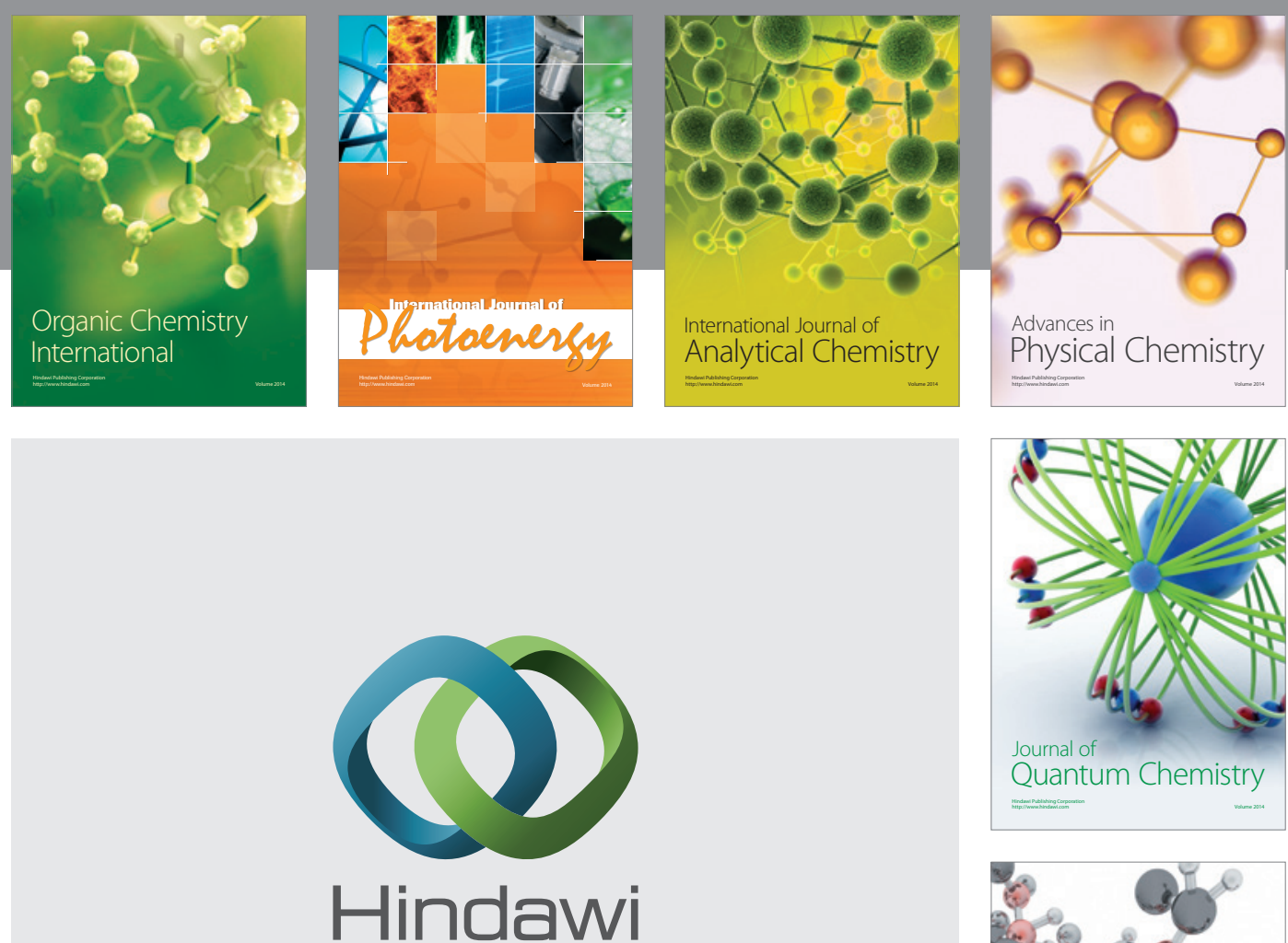

Submit your manuscripts at

http://www.hindawi.com

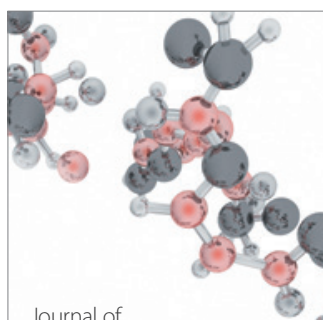

Analytical Methods

in Chemistry

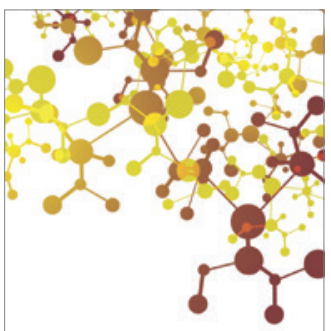

Journal of

Applied Chemistry

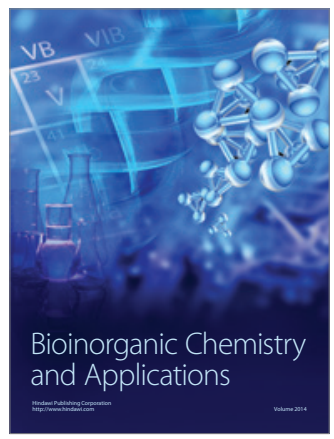

Inorganic Chemistry
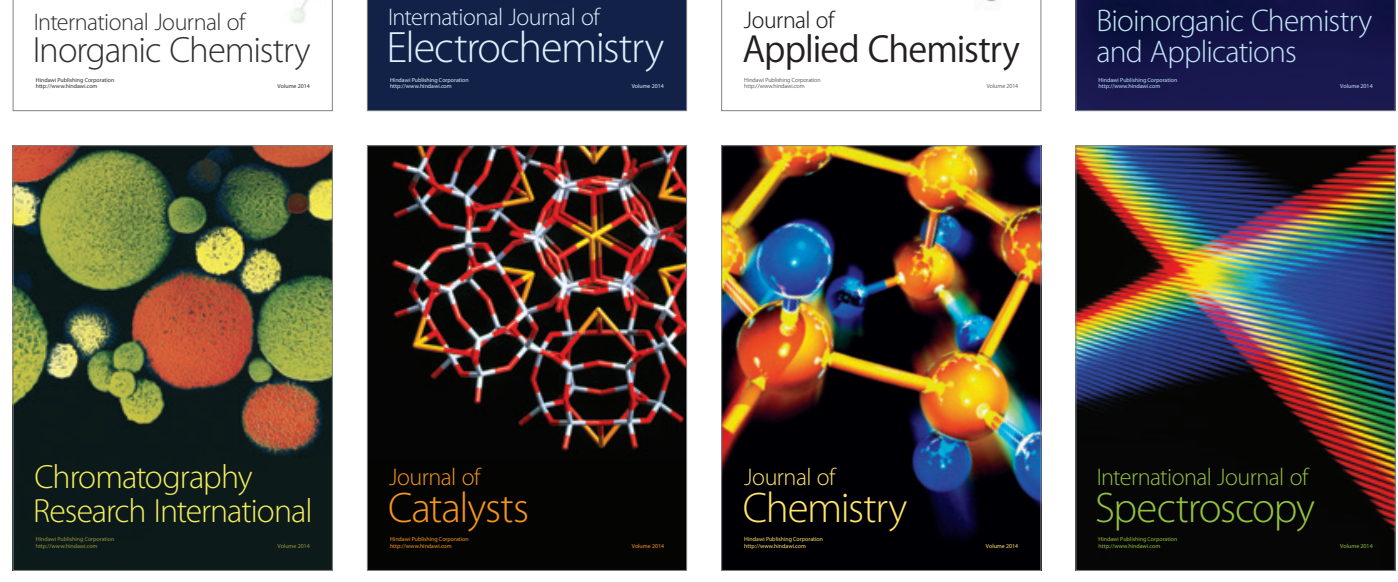